\title{
Quality of life measures in older adults after traumatic brain injury: a systematic review
}

\author{
Cindy Hunt ${ }^{1}$ (D) Shatabdy Zahid ${ }^{2} \cdot$ Naomi Ennis $^{3} \cdot$ Alicja Michalak $^{1} \cdot$ Cheryl Masanic $^{4} \cdot$ Chantal Vaidyanath $^{4}$. \\ Shree Bhalerao ${ }^{7} \cdot$ Michael D. Cusimano $^{5} \cdot$ Andrew Baker $^{6}$
}

Accepted: 7 September 2019 / Published online: 14 September 2019

(c) The Author(s) 2019

\begin{abstract}
Background On average older adults experiencing TBI are hospitalized four times as often, have longer hospital stays, and experience slower recovery trajectories and worse functional outcomes compared to younger populations with the same injury severity. A standard measure of Qol for older adults with TBI would facilitate accurate and reliable data across the individual patient care continuum and across clinical care settings, as well as support more rigorous research studies of metadata.

Purpose The aim of this systematic review was to investigate patient reported Qol measures in studies with older adults post TBI.

Method A systematic review was carried out focusing on the various tools to measure Qol in older adults, $\geq 65$ years of age with a diagnosis of TBI. Data bases searched included Medline, Embase, PubMed, CINAHL, and PsychInfo from date of inception to September 25, 2017.

Results A total of 20 articles met the inclusion criteria. Nine different tools were identified.

Conclusions Findings based on the comparison of reliability and construct validity of the Qol measures reported in this review suggest that no single instrument is superior to all others for our study population. Future research in this field should include the enrollment of larger study samples of older adults. Without these future efforts, the ability to detect an optimal Qol measure will be hindered.
\end{abstract}

Keywords Traumatic brain injury $\cdot$ Quality of life $\cdot$ Literature review $\cdot$ Older adult

Cindy Hunt

Cindy.Hunt@unityhealth.to

Shatabdy Zahid

shatabdy.zahid@mail.utoronto.ca

Naomi Ennis

ennisnaomi@gmail.com

Alicja Michalak

Alicja.Michalaka@unityhealth.to

Cheryl Masanic

Cheryl.Masanic@uhn.ca

Chantal Vaidyanath

Chantal.Vaidyanath@uhn.ca

Shree Bhalerao

Shree.Bhalerao@unityhealth.to

Michael D. Cusimano

Michael.Cusimano@unityhealth.to

Andrew Baker

Andrew.Baker@unityhealth.to
1 Head Injury Clinic, Trauma and Neurosurgery Program, St. Michael's Hospital, Dalla Lana School of Public Health, University of Toronto, Toronto, ON, Canada

2 University of Toronto, Toronto, ON, Canada

3 Department of Psychology, Ryerson University, Toronto, ON, Canada

4 St. Michael's Head Injury Clinic and UHN Toronto Rehabilitation Clinic Toronto, Toronto, ON, Canada

5 Department of Surgery, Division of Neurosurgery, Injury Prevention Research Office, Keenan Research Centre, St. Michael's Hospital, University of Toronto, Toronto, ON, Canada

6 Departments of Anesthesia and Critical Care, Keenan Research Centre for Biomedical Science, St. Michael's Hospital Toronto, University of Toronto, Toronto, ON, Canada

7 St. Michael's Head Injury Clinic, Toronto, ON, Canada 


\section{Background}

The rate of hospitalization among older adults ( $\geq 65$ years of age) with traumatic brain injury (TBI) has increased by $24 \%$ over the past decade [1]. On average, older adults with TBI are hospitalized four times as often, have longer hospital stays [2], and experience slower recovery trajectories and worse functional outcomes compared to younger populations with the same injury severity after TBI [3]. The economic cost of TBI is expected to rise from $\$ 7.3$ billion in 2011 to $\$ 8.2$ billion (CAD) in 2021 [2]. Much of what has been studied about the personal impact of TBI on older adult quality of life (Qol) - both in acute and rehabilitative care-has been based on symptom reduction or information provided by family or clinician ratings. Only recently, has the importance of the patient's perspective on Qol become a critical indicator following TBI [4, 5]. Qol is conceptualized as self-reported overall contentment across different areas of life, including physical well-being, social relationships, community activities and recreation, and personal fulfillment [6]. Reviews with a focus on childhood TBI highlight the challenges of drawing conclusions across studies when study measures differ [7-9]. Trauma in older adult patients has been insufficiently studied [10]. The lack of a standard Qol measure for older adults contributes to this knowledge deficit. Implementing a common measure of Qol can help improve the care received by the older adults and increase our understanding of their unique needs.

A standardized Qol measure would assess the effectiveness of interventions [5, 11]. A standardized Qol measurement for older adults post TBI could improve clinical practice, enhance health care delivery, inform health policy, and support allocation of health service funds [12]. Local-level [13] and international [14] TBI research has recognized the importance of using standardized measures to improve data quality and patient care. A standard QoL measure for older adults with TBI could facilitate accurate and reliable data within an individual patient care continuum and across clinical care settings, and support more rigorous research studies with metadata.

We conducted a systematic review with the aim to identify Qol measurement tools used for older adults post TBI, and examined the psychometric properties and feasibility of administration among older adults, to aid in the identification of a standardized Qol tool for this population.

\section{Methods}

The systematic literature review followed the Preferred Reporting Items for Systemic Review and Meta-Analysis (PRISMA) statement [15]. The study protocol was documented in PROSPERO [16], Registration Number: CRD42018092730.

\section{Study eligibility criteria}

The studies met the following inclusion criteria:

1. Study participants experienced TBI of any severity (mild, moderate, severe);

2. The study author explicitly referred to the tool as measuring Qol;

3. The Qol measure assessed more than one domain;

4. Evidence of at least 5 study participants that were $\geq 65$ years at time of Qol assessment;

5. If a study included adults with conditions other than TBI, data on the participants with TBI must have been examined and reported separately from other group(s).

\section{Information sources}

Search terms for the databases were first developed by the authors in consultation with an information specialist. Our population included various terms for older adults such as "aged," "pensioner," and "aged 65 years and above." We included search terms for quality of life measures such as specifying tools, health indicators, and health-related quality of life (see Appendix). The computerized search strategy was peer-reviewed by a second information specialist in accordance with PRISMA guidelines. Once approved, the search was conducted in the following databases: Medline, Embase, PubMed, CINAHL, and PsychInfo from date of inception to September 25, 2017. The search was limited to the English language. The full electronic search strategy for one database (Medline) is presented in Appendix.

\section{Study selection}

Three researchers $(\mathrm{CH}, \mathrm{NE}, \mathrm{SZ})$ independently screened 3586 titles and abstracts against the inclusion criteria. We discussed our individual results, and disagreements were resolved through consensus. In total, 508 full texts were assessed for eligibility. After full-text review, we yielded 20 studies for quality assessment and data abstraction.

Two authors $(\mathrm{CH}, \mathrm{SZ})$ independently reviewed the included full-text studies and extracted information to a spreadsheet listing geographic location, level of care, study 
design, sample size, participant characteristics: sex, mean age of study participants, age range, frequency and proportion of total participants aged 65 and older, and TBI severity (mild, moderate, or severe). Data on Qol instruments was extracted from each study and recorded by name of Qol measure(s), type and number of dimensions, administrative time point(s), psychometric properties using the COSMIN guideline [17], and feasibility among older adults. Data were abstracted into the spreadsheet independently and disagreements were resolved through consensus.

\section{Quality assessment of individual studies}

The Downs and Black checklist [18] with revisions [19-21] was used to evaluate methodological quality of each study that met the criteria for quality assessment. Revisions to the Downs and Black [18] checklist for non-intervention studies entailed removal of items $4,8,13,14,15,19,21-24$ inclusive, because the items were not relevant to observational studies. Item number 5 was re-valued to have potential value of 2 points if the study included socioeconomic status as a confounder among others, 1 point if it mentioned confounders but not socioeconomic status, and 0 points if it did not mention any confounders. Socioeconomic status is an important confounder to consider as it affects accessibility to services among older adults [11]. Item 27 which addressed statistical power and scoring was simplified from a 5-point scale to a 0 or 1 point score. One point was awarded if the study power or sample size was reported and a score of 0 was awarded where no sample size, no power calculation, or no explanation as to whether the number of subjects was appropriate for the question being asked was reported [11]. Higher scores on the Downs and Black checklist indicated a greater degree of methodological quality. Given the revisions, each study could achieve a maximum score of 18 points. The exception to the revisions was a single randomized clinical trial study [22]. As such, all items on the Downs and Black checklist were included in the quality assessment, which had a total potential score of 28 points. Inter-rater reliability measured by Cohen's Kappa $=.84$ between the two authors completing the quality assessment data [23] with disagreements resolved by discussion. Qol measures were considered if one additional publication tested the psychometrics of the specific Qol measure.

\section{Results}

\section{Study selection}

The search yielded 3607 articles, of these 21 were duplicates, and 3078 were excluded based on the titles and abstracts that failed to meet inclusion and exclusion criteria, thereby leaving 508 full-text articles to be assessed for eligibility. After assessing eligibility of full-text articles, we included 20 studies for quality assessment and data abstraction [22, 24-42]. The PRISMA flow diagram is shown in Fig. 1. Eight papers identified in the search included older adults according to the age range, but did not report the number of adults, $\geq 65$ years. The authors were contacted by email in order to identify if the paper met our review inclusion criteria of 5 or more older adults. However, we did not receive a response and these studies were excluded.

\section{Study characteristics}

\section{Geographical location, level of care, and study design}

The studies selected for review represented 12 different populations worldwide. These included United States [25, 29, 30, 34, 36, 39, 41], Canada [31, 38], England [27, 40], Spain [33], Brazil [42], France [24], Switzerland [28], Taiwan [32], Sweden [22], Germany [35], Netherlands [26], and China [26] (Table 1). Levels of care among the 20 studies included 10 community care environments $[25,29,30$, 35-37, 39-42], 8 hospital settings [22, 26-28, 31, 33, 34, 38 ], and 2 studies that recruited participants from both community and hospital $[24,32]$. Half of the studies were cohort design [25-28, 31, 32, 36, 38, 39, 42], nine were cross sectional surveys [25, 29, 30, 33, 35, 37, 40, 41], and one was a randomized control trial [22]. Pickelsimer et al. [36] and Selassie et al. [37] used the same study sample, which was determined based on the review of the sample size, mean age of study participants, site of data collection, and contributing authors. Therefore, our review contained 19 unique study samples.

\section{Older adult study participants}

Only two studies [31, 32] exclusively examined older adults ( $\geq 65$ years). In two studies, three-quarters of the study sample consisted of older adults $[33,39]$. In contrast, six studies reported fewer than of $10 \%$ of the study sample to be older adults $[22,24,27,35,41,42]$. For ten studies in the review, $11-30 \%$ of the sample included older adults $[25,26,28-30$, 34, 36-38, 40]. Among 17 studies, less than half of the participants were female [24-30, 32-42], whereas two studies consisted of 55\% females [22] and in one study $60 \%$ [31] were female participants.

\section{Identification of Qol measures}

Nine different Qol measures were identified among the 20 studies in the review, see Table 2. Seven main tools and two of the seven tools were abbreviated tools (SF-36 and SF-12 and the QOLIBRI with QOLIBRI-OS). Slightly more than 


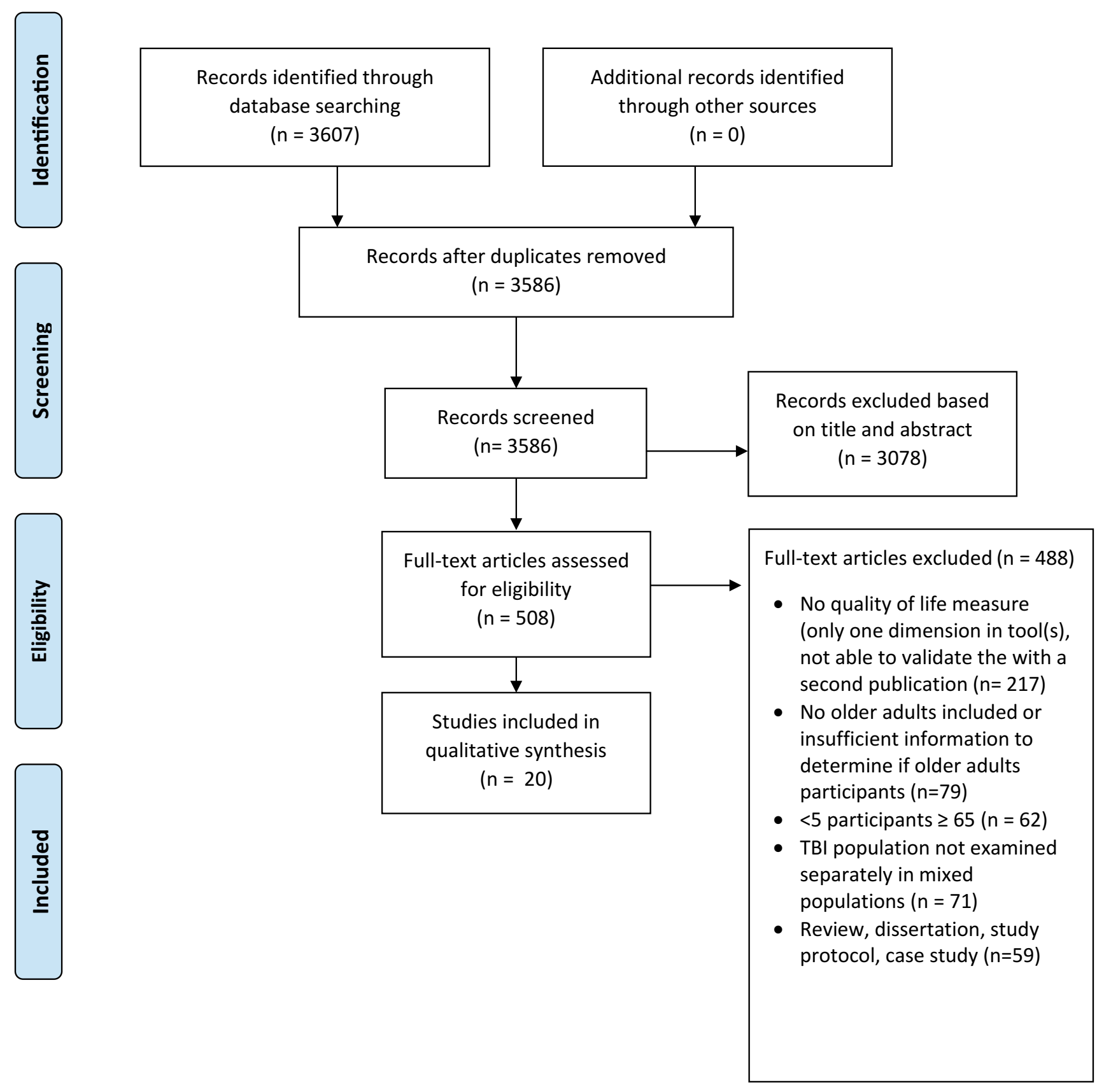

Fig. 1 PRISMA Flowchart of studies

half $(11 / 20)$ of all studies reported using the Short Form Health Survey (9/11 used the SF-36 [22, 26, 29, 30, 33, 34, 36, 37, 39], while 2/11 used the short version SF-12[28, 31]). The Quality of Life after Brain Injury (QOLIBRI) measure was implemented in four studies; [24, 32, 35, 40], one of which used the 6 item QOLIBRI-OS [35]. The QOLIBRIOS correlates well to the full QOLIBRI $(r=0.87)$ [43]. The World Health Organization Quality of Life BREF (WHOQol BREF) [32, 42] and the EuroQol-5D (EQ-5D) [27, 33] were each implemented two studies. The NeuoQol [41],
Sickness Impact Profile (SIP) [38], and Flanagan Quality of Life Scale (FQolS) [25] were used in three studies. Three studies implemented two measures of Qol. The combinations of Qol measures included: QOLIBRI and WHO-QoL BREF [32], SF-36 and EQ-5D [33], and SF-36 and SIP[37].

\section{TBI severity and Qol measure}

Studies reporting TBI severity are illustrated in Fig. 2. Six studies included participants with all types of TBI 
Table 1 Study characteristics

\begin{tabular}{|c|c|c|c|c|c|c|c|}
\hline Author (year) & $\begin{array}{l}\text { Geographical } \\
\text { location and level } \\
\text { of care }\end{array}$ & Study design & $\begin{array}{l}\text { \# of TBI partici- } \\
\text { pants }(n) \\
\text { Mean age (SD) }\end{array}$ & Males $(n, \%)$ & $\begin{array}{l}\text { Seniors }>65 \\
(n, \%)\end{array}$ & $\begin{array}{l}\text { Quality of life } \\
\text { measure }\end{array}$ & $\begin{array}{l}\text { Quality } \\
\text { Assess- } \\
\text { ment } \\
\text { Score/18 }\end{array}$ \\
\hline $\begin{array}{l}\text { Azouvi et al. } \\
\text { (2016) [24] }\end{array}$ & $\begin{array}{l}\text { Paris, France, } \\
\text { Hospital and } \\
\text { Community }\end{array}$ & $\begin{array}{l}\text { Prospective } \\
\text { cohort }\end{array}$ & $\begin{array}{l}85 \\
42(20)\end{array}$ & $69,81.18 \%$ & $9,10.59 \%$ & QOLIBRI & 12 \\
\hline $\begin{array}{l}\text { Brown et al. } \\
\text { (2004) [25] }\end{array}$ & $\begin{array}{l}\text { New York, USA } \\
\text { Community }\end{array}$ & Cross sectional & $\begin{array}{l}200 \\
38.2(16.0)\end{array}$ & $147,55 \%$ & $\begin{array}{l}24 \text { (range 60-99) } \\
5.29 \%\end{array}$ & $\begin{array}{l}\text { Flanagan QOL } \\
\text { Scale }\end{array}$ & 13 \\
\hline $\begin{array}{l}\text { Cnossen et al. } \\
\text { (2017) [26] }\end{array}$ & $\begin{array}{l}\text { Netherlands } \\
\text { (NH); China } \\
(\mathrm{CH}) \\
\text { Hospital }\end{array}$ & $\begin{array}{l}\text { Prospective } \\
\text { cohort }(\mathrm{NH}) ; \\
\text { Retrospective } \\
\text { Cohort }(\mathrm{CH})\end{array}$ & $\begin{array}{l}\text { NH: } 447 \\
46(27-58) \\
\text { CH: } 173 \\
35(24-50)\end{array}$ & $\begin{array}{l}\text { NH: } 286,64 \% \\
\text { CH: } 116,67 \%\end{array}$ & $\begin{array}{l}\text { NH: } 63,14.1 \% \\
\text { CH: } 15,8.7 \%\end{array}$ & SF-36 & 13 \\
\hline $\begin{array}{l}\text { Grieve et al. } \\
\text { (2016) [27] }\end{array}$ & $\begin{array}{l}\text { UK } \\
\text { Hospital (Critical } \\
\text { Care) }\end{array}$ & Cohort & $\begin{array}{l}3512 \\
\text { One mean NR }\end{array}$ & $2687,76.51 \%$ & $86,2.45 \%(70+)$ & EQ-5D & 11 \\
\hline $\begin{array}{l}\text { Haller et al. } \\
\text { (2016) [28] }\end{array}$ & $\begin{array}{l}\text { Switzerland } \\
\text { Hospital }\end{array}$ & $\begin{array}{l}\text { Prospective } \\
\text { cohort }\end{array}$ & $\begin{array}{l}351 \\
\text { Older group } 74 \\
\quad(70-80)\end{array}$ & $257,73.22 \%$ & $97,27.64 \%$ & SF-12 & 14 \\
\hline $\begin{array}{l}\text { Horner et al. } \\
\text { (2005) [29] }\end{array}$ & $\begin{array}{l}\text { South Carolina, } \\
\text { USA } \\
\text { Community }\end{array}$ & Cross sectional & $\begin{array}{l}1606 \\
\text { NR }\end{array}$ & $983,61.20 \%$ & $292,18.2 \%$ & SF-36 & 16 \\
\hline $\begin{array}{l}\text { Horner et al. } \\
\text { (2008) [30] }\end{array}$ & $\begin{array}{l}\text { South Carolina, } \\
\text { USA } \\
\text { Community }\end{array}$ & Cross sectional & $\begin{array}{l}1560 \\
\text { NR }\end{array}$ & $953,61.09 \%$ & $287,18.40 \%$ & SF-36 & 17 \\
\hline $\begin{array}{l}\text { Kristman et al. } \\
\text { (2016) [31] }\end{array}$ & $\begin{array}{l}\text { Thunder Bay } \\
\text { and Kingston, } \\
\text { Canada } \\
\text { Hospital (ED) }\end{array}$ & $\begin{array}{l}\text { Prospective } \\
\text { cohort }\end{array}$ & $\begin{array}{l}46 \\
76.2(7.4)\end{array}$ & $19,41.30 \%$ & $46,100 \%$ & SF-12 & 17 \\
\hline $\begin{array}{l}\text { Lin et al. (2016) } \\
\text { [32] }\end{array}$ & $\begin{array}{l}\text { Taipei, Taiwan } \\
\text { Hospital and } \\
\text { Community }\end{array}$ & $\begin{array}{l}\text { Cohort (subset of } \\
\text { survey data) }\end{array}$ & $\begin{array}{l}333 \\
75.8(8.4)\end{array}$ & $169,50.8 \%$ & $\begin{array}{l}333 \text { (range } \\
\quad 60-99 \text { ), } 100 \%\end{array}$ & $\begin{array}{l}\text { QOLIBRI and } \\
\text { WHO-QOL } \\
\text { BREF }\end{array}$ & 7 \\
\hline $\begin{array}{l}\text { Mar et al. (2011) } \\
\text { [33] }\end{array}$ & $\begin{array}{l}\text { Basque Country } \\
\text { and Navarre, } \\
\text { Spain } \\
\text { Hospital }\end{array}$ & Cross sectional & $\begin{array}{l}68 \\
\text { NR }\end{array}$ & $37,54 \%$ & $48,70.6 \%$ & $\begin{array}{l}\text { SF-36 and } \\
\text { EQ-5D }\end{array}$ & 14 \\
\hline $\begin{array}{l}\text { Matuseviciene } \\
\text { et al. (2016) } \\
\text { [22] }\end{array}$ & $\begin{array}{l}\text { Sweden } \\
\text { Hospital (ED) }\end{array}$ & $\begin{array}{l}\text { Randomized } \\
\text { Control Trial }\end{array}$ & $\begin{array}{l}173 \\
\text { Single mean NR }\end{array}$ & $78,45.09 \%$ & $14,8.09 \%$ & SF-36 & $\begin{array}{c}19 * \text { total } \\
\text { pos- } \\
\text { sible } \\
\text { score } \\
\text { of } 28\end{array}$ \\
\hline $\begin{array}{l}\text { McCarthy et al. } \\
\text { (2006) [34] }\end{array}$ & $\begin{array}{l}\text { South Carolina, } \\
\text { USA } \\
\text { Hospital }\end{array}$ & $\begin{array}{l}\text { Retrospective } \\
\text { cohort }\end{array}$ & $\begin{array}{l}\text { 7612(weighted) } \\
43.2(20.0)\end{array}$ & $4865,63.9 \%^{\mathrm{a}}$ & $\begin{array}{l}2272,29.85 \%^{\mathrm{a}} \\
(\text { range } 55-75+)\end{array}$ & SF-36 & 15 \\
\hline $\begin{array}{l}\text { Muehlan et al. } \\
\text { (2016) [35] }\end{array}$ & $\begin{array}{l}\text { Germany } \\
\text { Community }\end{array}$ & Cross sectional & $\begin{array}{l}795 \\
\text { NR }\end{array}$ & NR & $27,3.40 \%$ & QOLIBRI-OS & 10 \\
\hline $\begin{array}{l}\text { Pickelsmier et al. } \\
\text { (2006) [36] }\end{array}$ & $\begin{array}{l}\text { South Carolina, } \\
\text { USA } \\
\text { Community }\end{array}$ & $\begin{array}{l}\text { Prospective } \\
\text { cohort }\end{array}$ & $\begin{array}{l}2118 \\
\text { NR }\end{array}$ & $1284,60.6 \%$ & $500,23.61 \%$ & SF-36 & 17 \\
\hline $\begin{array}{r}\text { Selassie et al. } \\
\text { (2009) [37] }\end{array}$ & $\begin{array}{l}\text { South Carolina, } \\
\text { USA } \\
\text { Community }\end{array}$ & Cross sectional & $\begin{array}{l}2118 \\
\text { NR }\end{array}$ & $1284,60.6 \%$ & $500,23.61 \%$ & SF-36 and SIP & 12 \\
\hline $\begin{array}{l}\text { Stambrook et al. } \\
\text { (1993) [38] }\end{array}$ & $\begin{array}{l}\text { Manitoba, } \\
\text { Canada } \\
\text { Hospital }\end{array}$ & Cohort & $\begin{array}{l}106 \\
\text { Single mean NR }\end{array}$ & $106,100 \%$ & $12(11.3 \%)$ & $\begin{array}{l}\text { Sickness Impact } \\
\text { Profile (SIP) }\end{array}$ & 11 \\
\hline $\begin{array}{l}\text { Thompson et al. } \\
\text { (2012) [39] }\end{array}$ & $\begin{array}{l}14 \text { states, USA } \\
\text { Community }\end{array}$ & $\begin{array}{l}\text { Prospective } \\
\text { cohort }\end{array}$ & $\begin{array}{l}414 \\
\text { NR }\end{array}$ & $246,59.3 \%$ & $309,74.64 \%$ & SF-36 & 16 \\
\hline $\begin{array}{l}\text { Toman et al. } \\
\text { (2017) [40] }\end{array}$ & $\begin{array}{l}\text { Birmingham, UK } \\
\text { Community }\end{array}$ & Cross sectional & $\begin{array}{l}124 \\
\text { NR }\end{array}$ & $95,76.61 \%$ & $17,13.71 \%$ & QOLIBRI & 11 \\
\hline
\end{tabular}


Table 1 (continued)

\begin{tabular}{|c|c|c|c|c|c|c|c|}
\hline Author (year) & $\begin{array}{l}\text { Geographical } \\
\text { location and level } \\
\text { of care }\end{array}$ & Study design & $\begin{array}{l}\text { \# of TBI partici- } \\
\text { pants }(n) \\
\text { Mean age (SD) }\end{array}$ & Males $(n, \%)$ & $\begin{array}{l}\text { Seniors }>65 \\
(n, \%)\end{array}$ & $\begin{array}{l}\text { Quality of life } \\
\text { measure }\end{array}$ & $\begin{array}{l}\text { Quality } \\
\text { Assess- } \\
\text { ment } \\
\text { Score/18 }\end{array}$ \\
\hline $\begin{array}{l}\text { Toyinbo et al. } \\
\text { (2016) [41] }\end{array}$ & $\begin{array}{l}\text { Florida, USA } \\
\text { Community }\end{array}$ & Cross sectional & $\begin{array}{l}485 \\
35.0(10.6)\end{array}$ & $454,93.61 \%$ & $9,1.86 \%$ & NeuroQOL & 8 \\
\hline $\begin{array}{l}\text { Weber et al. } \\
\text { (2015) [42] }\end{array}$ & $\begin{array}{l}\text { Brazil } \\
\text { Community }\end{array}$ & $\begin{array}{l}\text { Prospective } \\
\text { cohort }\end{array}$ & $\begin{array}{l}50 \\
N R\end{array}$ & $44,88 \%$ & $\begin{array}{l}5 \text { (range } 66-85), \\
10 \%\end{array}$ & $\begin{array}{l}\text { WHO-QOL } \\
\text { BREF }\end{array}$ & 9 \\
\hline
\end{tabular}

severity (mild, moderate, severe) [27, 34, 36, 37, 40, 42]. The measures of Qol across these six studies varied. One study used the EQ-5D [27], two studies the SF-36,[34, 36] while another used SF-36 in combination with the SIP[37], one study used the QOLIBRI [40], and one the WHO-QoL BREF [42]. Of all 20 studies reviewed 14 reported some participants with mild TBI and among these studies about half (8/14) used the SF tools, SF-36 [22, 26, 28, 29, 34-37] and SF-12 [31], while the remaining 6/14 studies used FQolS [25], EQ-5D [27], WHO-Qol BREF and QOLIBRI together [32], QOLIBRI [40], NeuroQol [41], and the WHOQol BREF[42]. This review included a total of 7393 mild TBI participants, 3357 moderate TBI participants, and 10,114 severe TBI participants. The Qol measure dimensions including categories, total number of items measured, and the type of measure (general of specific) are presented in Table 2.

\section{Qol tool administration}

Qol measures were administered by four different methods (phone, on-site interview, self-report, and surface mail). A total of seven different time points post injury (PI) were identified for Qol administration. Times included 0-30 days PI, $1+$ to 3 months PI, 3 + to 6 months PI, $6+$ to 12 months PI, $1+$ to 3 years PI, $3+$ to 5 years, and over 5 years PI). Four studies administered Qol measures across two time points [28, 31, 32, 39] and undertook comparison of Qol in the study analysis over time.

\section{Qualities of instruments and studies}

Psychometric properties, using the COSMIN guideline, and feasibility of the Qol tool usage to older adults with TBI are presented in Table 2 . We selected 22 articles to review the psychometric properties (reliability, validity, and feasibility in the older adult population with TBI) for the nine Qol measures we identified in this systematic review (see Table 2). Noted here are the references specifically used to develop Table 2, listed by each Qol measure with orientation to the specific article reviewed (and in this order) for validity, reliability, and feasibility: SF-36 and SF-12: Table 2 references
[44-46]; WHO-Qol BREF: Table 2 references [44, 47], QOLIBRI, QOLIBRI-OS; Table 2 references [43, 48-50]; EuroQol: Table 2 references [44, 51-53]; SIP: Table 2 references [54-57]; Flanagan QOLS: Table 2 references [58, 59]; NeuroQol: Table 2 references [46, 60-63]. Construct or criteria validity was identified in the literature for six toolsSF-12 and 36, WHO-QoL BREF, QOLIBRI-OS, EQ-5D, SIP, NeuroQol, while reliability through test-retest methods and/or internal consistency was identified in the literature for six tools-WHO-Qol BREF, QOLIBRI, EQ-5D, SIP, Flanagan Quality of Life Scale, and NeuroQoL. Four of the seven tools were free to use, two required a licensing fee, and one of the tools is free to use after acquiring copyright permission. Each of the tools attempted to capture a range of physical, emotional, social/community, and spiritual health dimensions. Only the QOLIBRI is specific for brain injuries and captures the social relationships, emotions, physical problems, and self-domains of health. However, a prior study suggested that the QOLIBRI has missing questions regarding potential occurrences of seizures, legal issues, driving abilities, stigma, and sleeping problems. The SF-36, SF-12, and SIP have been validated for use within the TBI population and asks questions mainly regarding physical, social, and emotional/mental health. However, these tools have only been validated for and used mainly among younger TBI populations. All the Qol tools were self-reported and use Likert scales. Completion of each tool is estimated at less than ten minutes with the exception of SIP.

The Downs and Black with revision scores $[5,18,20]$ are reported in Table 1 with detailed item specific scores in Table 3. The average score was $12.8 / 18$ with a range of 7-17 (not including the randomized clinical trial by Matuseviciene [22]). Common methodological limitations across studies included missing data, limited or insufficient data on validity, and study power not addressed.

\section{Discussion}

Older adults with TBI were not well represented in the literature when Qol is measured. Knowledge on the longer term impact of TBI on an individuals' Qol as they age is 


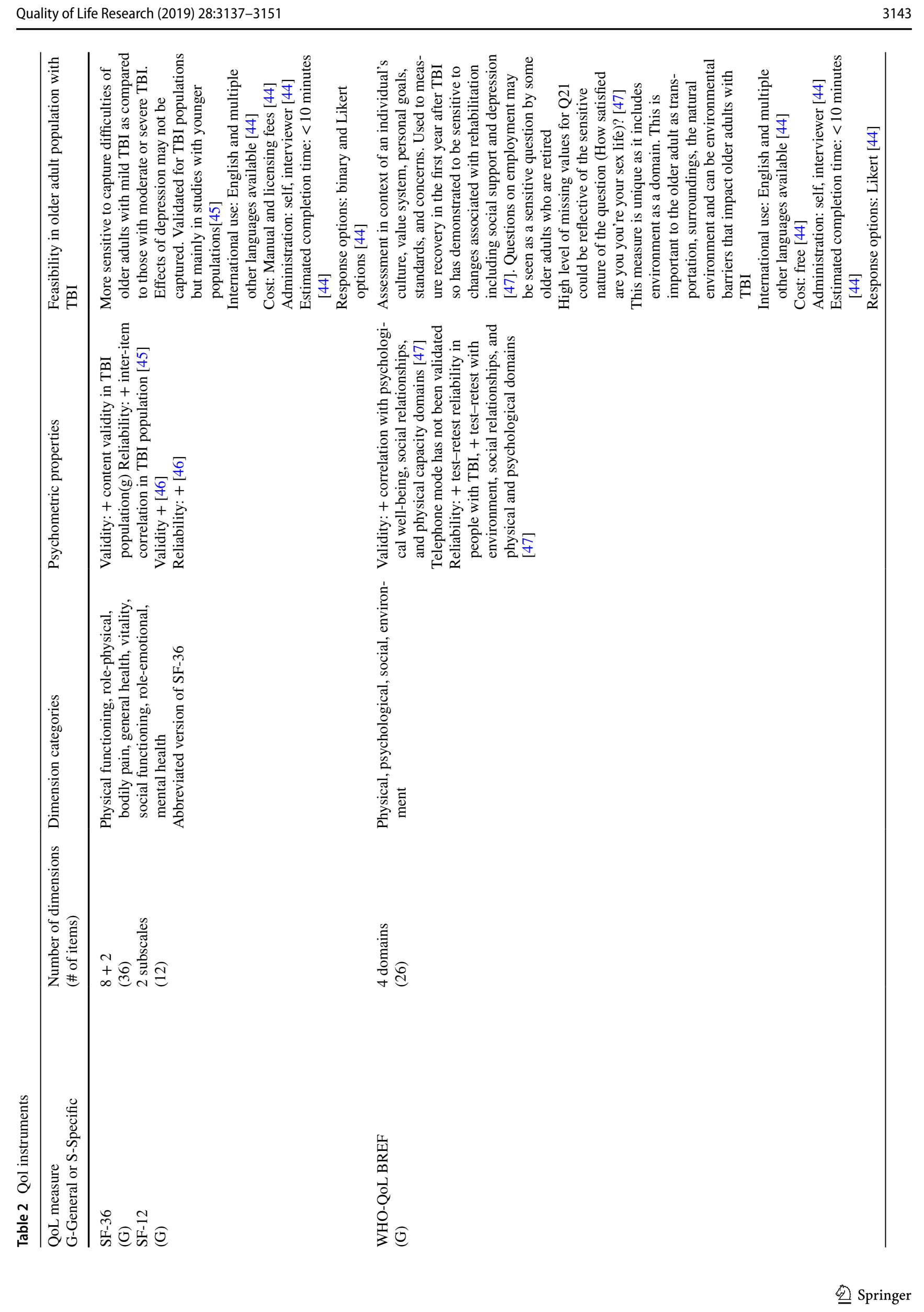




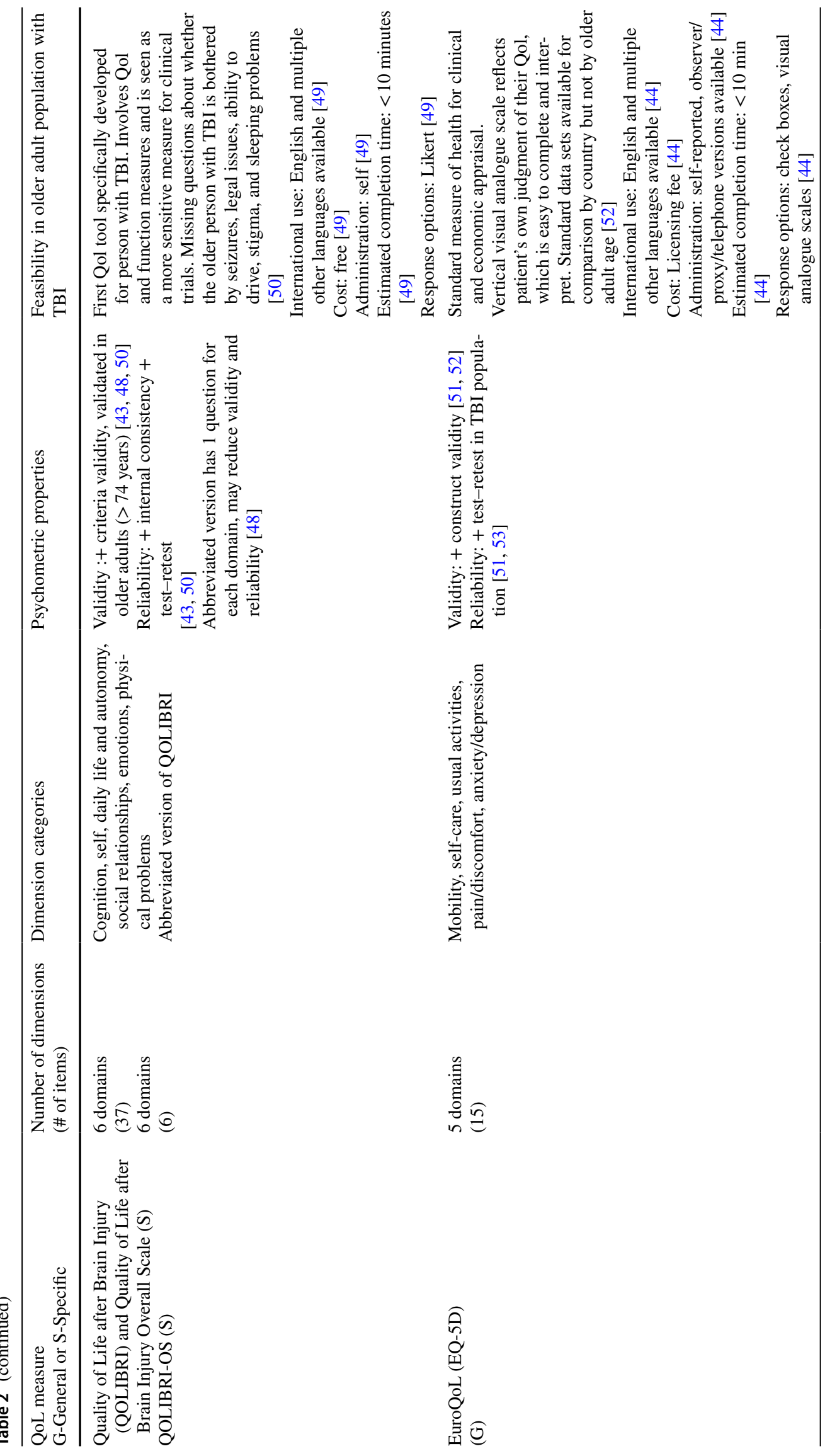




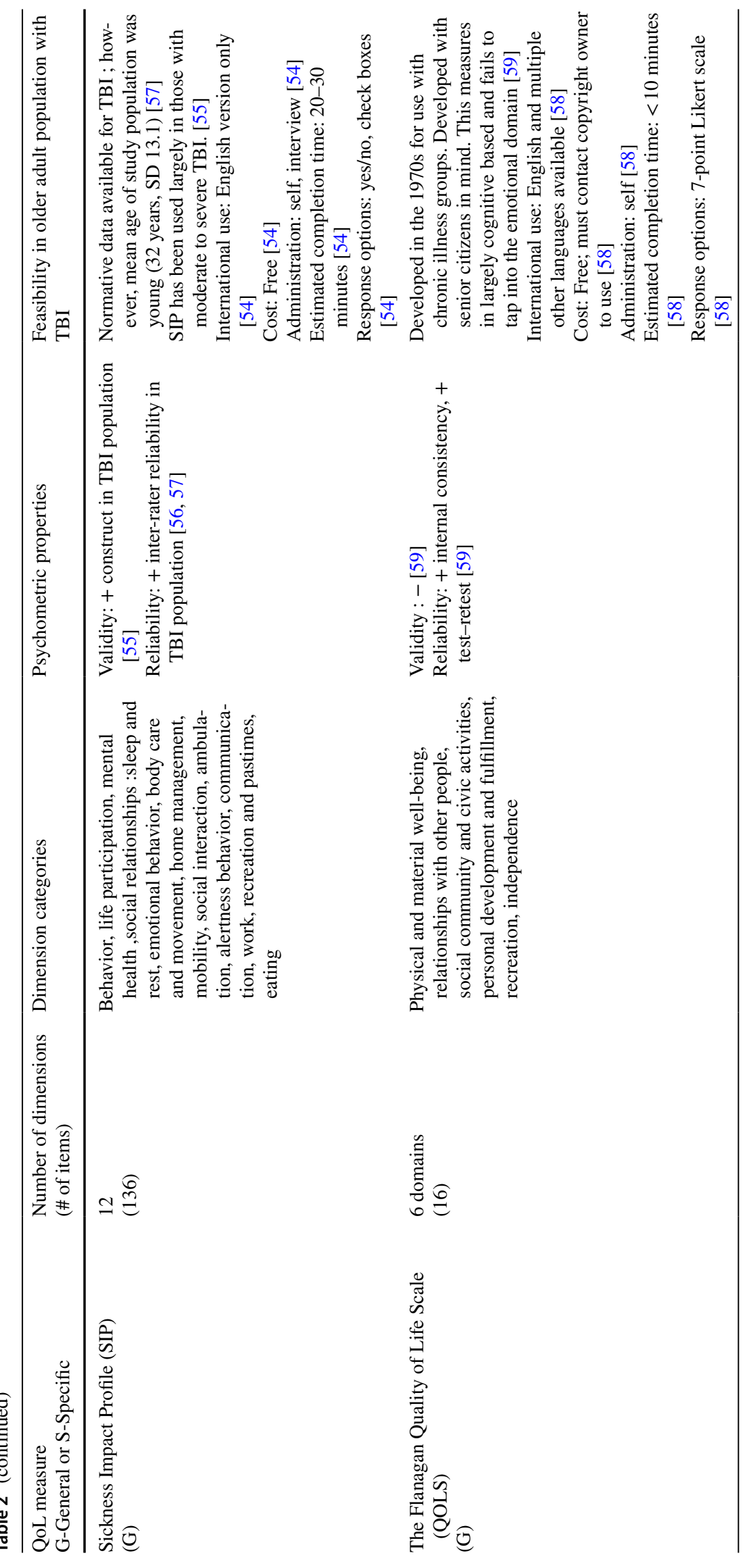




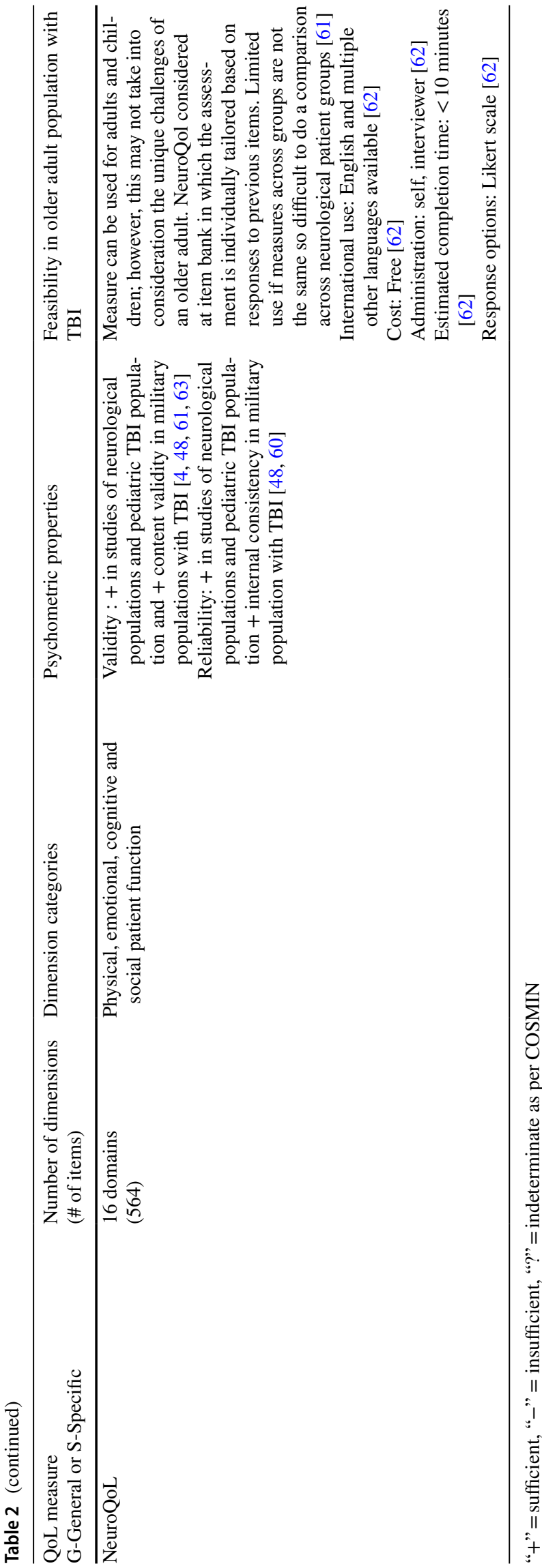

important information for all age groups. Extrapolating study findings to older adults from study samples weighted largely towards younger adults is inadequate, as older adult-specific findings are diluted. Older adult females were largely underrepresented in the studies we reviewed. Sex was often reported by total number of participants only and not by age, thereby making it difficult to determine the sex ratio of older adults. The lack of studies with older adult female participants is of particular importance as older females may have very different Qol needs as compared to older adult males [64]. Moreover, most studies in the review were conducted in major cities of higher income countries. Therefore, little is known about Qol for those older adults living in remote and lower income countries, who may experience limited access to health care resources and face other barriers that impact their Qol.

The systematic review identified nine Qol measurements ( 7 measures, with $2 / 7$ included abbreviated tools) used in studies that included older adults with TBI. Historically, Qol measures have fallen into two main categories: generic and disease/injury-specific tools [65]. Generic Qol measures are often used in health services research and population comparisons where the interest is in health status change across different diagnostic groups. In this review, seven of the nine Qol tools were generic measures (SF-36 and SF-12, WHO-Qol BREF, EQ-5D, SIP, FQolS, NeuroQol). The Short Form tools (SF-36, SF-12) have roots in the 1970s and have since been well documented for use in rehabilitation and many types of general diseases and injuries [66]. The EQ-5D tool has the added benefit of use in economic appraisal. It consists of 5 dimensions, is short and easy to complete, and has strong psychometric properties. It has been validated with a Canadian population and is recommended as a common data element for TBI by the National Institute of Neurological Disorders and Stroke [14]. Understanding the economic costs associated with Qol can be important given the strong financial impact of TBI on the health care system, particularly among older adults. Older adults with TBI have a rising number of emergency department visits, hospitalizations, and long recovery periods that require medical supervision $[2,13]$. The WHO-Qol BREF is recommended in the data repository for the Ontario Brain Institute [67]. The WHOQol BREF was the only measure that included the assessment of factors in the physical environment. The NeuroQol was developed to assess domains of physical, mental, and social functioning for adults with a variety of neurological conditions and is also included in the NIH Toolbox measures recommended for use in research, clinical, and educational settings [14]. The SIP and the FQolS have not been reported in the literature for the past decade with use in TBI patients. The domains of the Qol generic measures identified included a broad range of concepts: physical and 


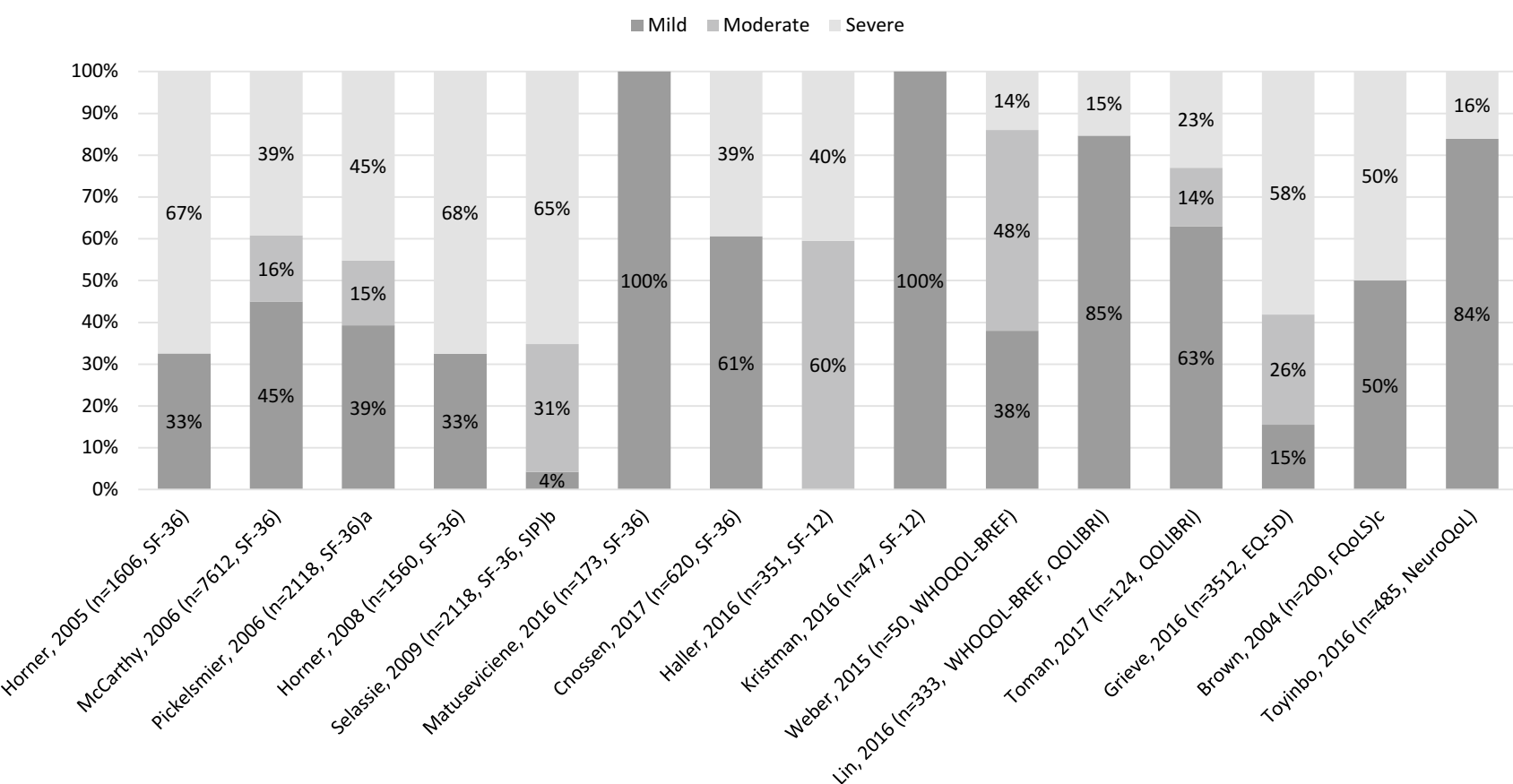

Fig. 2 Percentage of participants by TBI severity. Stambrook et al. [38], Mar et al. [33], Thompson et al. [39], Azouvi et al. [24] and Muehlan et al. [35], did not report traumatic brain injury severity. $a=$ study reported a sample size of 2118 people; reported severity scores

emotional health, self-care, pain, sleep and rest, activities of daily living, sexual functioning, and environment.

In contrast to generic tools are disease/injury-specific measures of Qol that are used by clinicians in practice to assess clinical changes within patients [65]. The disease/ injury-specific measure of Qol is generally responsive to clinical changes over time [65]. The QOLIBRI and abbreviated version QOLIBRI-OS were the only TBI-specific Qol instruments and were implemented in four studies [24, 32, $35,40]$. QOLIBRI is recommended for the general adult population of TBI by the National Institute of Neurological Disorders and Stroke [13]. It has the potential to identify specific consequences of a TBI injury and it can also detect the effects of interventions.

The importance of a common Qol measure for older adults with TBI is predicated on their unique characteristics, which includes changes in pathophysiology, higher incidence of general brain deterioration, co-morbid medical problems, reduced psychosocial and financial support, decreased motivation, and lowered expectations for recovery [14]. A suitable Qol measure must also take into consideration pre-injury disability. Dimensions that were not addressed in the either the generic or injury-specific measures reported but are worthy of future consideration in a common measure for the older adult post TBI include nutrition [68], medication use and quality of sleep [64], social cohesion and aspects of their built environment that could for 2098 people. $b=$ study reported a sample size of 2118 people; reported severity scores for 1947 people. $\mathrm{c}=$ study reported a sample size of 454 people; reported severity scores for 200 people.

affect safety [69], vision [70], and physical activity [71] and community engagement. Understanding the relationship between the older adults' individual needs and their physical environment may require both subjective and objective measures. For example, people with TBI regularly encounter physical barriers in the community such as steep slopes, stairs, curbs, and narrow pathways that can limit their performance and engagement in their community and subsequently impact their quality of life. One study in our review included both an injury-specific and generic measure of Qol [32] which may serve as a best practice approach for clinicians and researchers.

TBI is a highly heterogeneous injury by cause, severity, pathology, age, sex, clinical course, and patient outcomes. Based on the diversity of TBI outcomes by severity of injury, one could speculate that there may be need for TBI severity-specific Qol tools (i.e., tools specific to mild, moderate, or severe TBI). However, in the review no clear pattern emerged on Qol measurement tool use by TBI severity. We calculated the sum of all study participants in the review and found twice as many total study participants with moderate or severe TBI as compared to mild TBI. This is a concern as $80 \%$ of all TBIs are mild TBI and many are unreported, missed, or not assessed [16]. Challenges faced by researchers in the identification and recruitment of older adults with mild TBI may be the reason for this underrepresentation of older study subjects. Innovative methods are required to 
Table 3 Quality appraisal using Downs and Black [18] with revisions Baernholdt et al. [11], McHugh [23]

\begin{tabular}{|c|c|c|c|c|c|c|c|c|c|c|c|c|c|c|c|c|c|c|}
\hline & 1 & 2 & 3 & 5 & 6 & 7 & 9 & 10 & 11 & 12 & 16 & 17 & 18 & 20 & 25 & 26 & 27 & Total \\
\hline Azouvi et al. [24] & 1 & 1 & 1 & 1 & 1 & 1 & 0 & 0 & 0 & 1 & 1 & 1 & 1 & 1 & 0 & 1 & 0 & 12 \\
\hline Brown et al. [25] & 1 & 1 & 1 & 2 & 1 & 1 & 0 & 1 & 0 & 1 & 1 & 0 & 1 & 1 & 1 & 0 & 0 & 13 \\
\hline Cnossen et al. [26] & 1 & 1 & 1 & 0 & 1 & 1 & 1 & 1 & 1 & 1 & 1 & 0 & 1 & 1 & 0 & 1 & 0 & 13 \\
\hline Grieve et al. [27] & 1 & 1 & 1 & 1 & 1 & 1 & 0 & 0 & 1 & 0 & 1 & 1 & 1 & 1 & 0 & 0 & 0 & 11 \\
\hline Haller et al. [28] & 1 & 1 & 1 & 1 & 1 & 1 & 1 & 1 & 0 & 1 & 1 & 1 & 1 & 1 & 0 & 0 & 1 & 14 \\
\hline Horner et al. [29] & 1 & 1 & 1 & 2 & 1 & 1 & 1 & 1 & 0 & 1 & 1 & 1 & 1 & 1 & 0 & 1 & 1 & 16 \\
\hline Horner et al. [30] & 1 & 1 & 1 & 2 & 1 & 1 & 1 & 0 & 1 & 1 & 1 & 1 & 1 & 1 & 1 & 1 & 1 & 17 \\
\hline Kristman et al. [31] & 1 & 1 & 1 & 2 & 1 & 1 & 1 & 1 & 1 & 1 & 1 & 1 & 1 & 1 & 0 & 1 & 1 & 17 \\
\hline Lin et al. [32] & 0 & 1 & 1 & 0 & 0 & 0 & 0 & 1 & 0 & 1 & 1 & 0 & 1 & 1 & 0 & 0 & 0 & 7 \\
\hline Mar et al. [33] & 1 & 1 & 1 & 2 & 1 & 1 & 1 & 0 & 1 & 1 & 1 & 0 & 1 & 1 & 1 & 0 & 0 & 14 \\
\hline McCarthy et al. [34] & 1 & 1 & 1 & 2 & 1 & 1 & 1 & 0 & 0 & 1 & 1 & 0 & 1 & 1 & 1 & 1 & 1 & 15 \\
\hline Muehlan et al. [35] & 1 & 1 & 1 & 0 & 1 & 0 & 0 & 1 & 1 & 0 & 1 & 0 & 1 & 1 & 0 & 0 & 1 & 10 \\
\hline Pickelsimer et al. [36] & 1 & 1 & 1 & 2 & 1 & 1 & 1 & 0 & 1 & 1 & 1 & 1 & 1 & 1 & 1 & 1 & 1 & 17 \\
\hline Selassie et al. [37] & 1 & 1 & 1 & 1 & 1 & 1 & 0 & 1 & 1 & 0 & 1 & 1 & 1 & 1 & 0 & 0 & 0 & 12 \\
\hline Stambrook et al. [38] & 1 & 1 & 1 & 1 & 1 & 1 & 1 & 0 & 0 & 0 & 1 & 0 & 1 & 1 & 1 & 0 & 0 & 11 \\
\hline Thompson et al. [39] & 1 & 1 & 1 & 2 & 1 & 1 & 0 & 1 & 1 & 1 & 1 & 0 & 1 & 1 & 1 & 1 & 1 & 16 \\
\hline Toman et al. [40] & 1 & 1 & 1 & 0 & 1 & 1 & 0 & 1 & 1 & 0 & 1 & 0 & 1 & 1 & 1 & 0 & 0 & 11 \\
\hline Toyinbo et al. [41] & 1 & 1 & 1 & 0 & 1 & 0 & 0 & 0 & 0 & 1 & 1 & 0 & 1 & 1 & 0 & 0 & 0 & 8 \\
\hline Weber et al. [42] & 1 & 1 & 1 & 0 & 1 & 1 & 0 & 1 & 0 & 0 & 1 & 0 & 1 & 1 & 0 & 0 & 0 & 9 \\
\hline
\end{tabular}

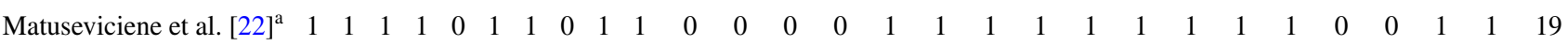

$0=$ no or unable to determine, $1=$ partially, 2 =yes for item 5 only. In the Downs and Black-revised, 17 categories were used to identify the quality of each study, and they were as follows: (1) Hypothesis described. (2) Main outcomes described. (3) Patient characteristics described. (5) Principle confounders in each group described. (6) Main findings described. (7) Random variability of main outcomes. (9) Patients lost to f/u described. (10) Probability values. (11) Subjects representative of population. (12) Subjects representative of population they are recruited. (16) Data dredging. (17) Consistency in follow-up timing. (18) Appropriate statistics. (20) Main outcome measures accurate. (25) Adequate adjustment for confounding. (26) Patients lost to follow-up accounted for. (27) Sufficient power calculation reported

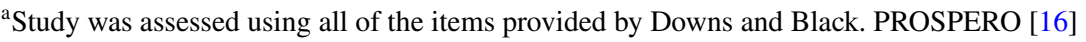

identify older adult patients with mild TBI for research studies, as they may not seek health care services, but may be suffering from a mild TBI in silence.

\section{Limitations}

Measuring Qol after TBI poses several significant methodological challenges. Unlike organ based diseases, where blood tests can help guide diagnosis and treatment, there are currently no rapid, definitive diagnostic test for TBI. Adding to this challenge is the fact that TBI is a group of injuries that are highly diverse by cause, severity, age, sex, symptoms, and premorbid history. The studies in this review represent a very broad spectrum of TBI care and recovery that can limit comparison and critical appraisal. In addition, there may be bias in the study sample over time as those who survive a TBI and return to the community may represent a select group of older adults with relatively fewer health problems, fewer cognitive, physical and emotional challenges, and better psychosocial support. The systematic review only included published studies in the English language. Although rigorous selection criteria were employed to ensure methodological quality and consistency, we were unable to confirm eight studies claiming the sample age range that included older adults actually meet the study criteria ( $>5$ adults $\geq 65$ years of age).

Our purpose was to identify the Qol measures used in older adult with TBI. The literature we selected to review on validity and reliability of the nine measures using the COSMIN criteria was not a comprehensive. However, it is worth considering that there may be limited evidence on the methodological strength of these instruments in the TBI population of older adults. No content mapping of the measures was included in the review to evaluate if domains of measures cover areas of importance to individuals with TBI. In addition, our review has limited information regarding the ability of the Qol measures to detect change and interpretability of measures. Further investigation of the Qol measures using the COSMIN criteria is warranted. 


\section{Conclusions}

We identified nine Qol measures that have been used in studies that included older adults with TBI. Findings based on the comparison of reliability and construct validity of the measures reported in this review suggest that no single instrument is superior to all others, for our study population. Future research in this field should include the enrollment of larger study samples of older adults. Without these future efforts, the ability to detect an optimal Qol measure will be hindered. As long as researchers and clinicians continue to use different tools to measure Qol, differences in outcomes could be a result of differences in measurement rather than understanding the unique rehabilitation needs of this population.

Acknowledgements The authors thank David Lightfoot PhD, the St. Michael's Hospital Information Specialist.

\section{Compliance with ethical standards}

Conflict of interest The authors declare that they have no conflict of interest.

Ethical approval This article is a systematic review and does not contain any studies with human participants performed by any of the authors.

Informed consent This article is a systematic literature view as such informed consent is not applicable.

Open Access This article is distributed under the terms of the Creative Commons Attribution 4.0 International License (http://creativeco mmons.org/licenses/by/4.0/), which permits unrestricted use, distribution, and reproduction in any medium, provided you give appropriate credit to the original author(s) and the source, provide a link to the Creative Commons license, and indicate if changes were made.

\section{Appendix}

Database: Ovid MEDLINE(R) In-Process and Other NonIndexed Citations and Ovid MEDLINE(R) $<1946$ to Present $>$ Search Strategy:

\begin{tabular}{ll}
\hline 1 & exp brain injuries/[including \\
& smaller terms: brain concus- \\
& sion, post concussive syndrome, \\
& brain hemorrhage, traumatic, \\
& brain injury chronic, diffuse \\
& axonal injury, pneumocephalus] \\
& $(49186)$ \\
& concuss $\$ . t i, a b . ~(3817)$ \\
& post?concussion.ti,ab. $(361)$ \\
4 & traumatic brain injur $\$ . t i, a b$. \\
& $(18503)$ \\
\hline
\end{tabular}

5

6

7

8

9

10

11

12 (brain injury adj2 traum\$).ti,ab. (17989)

tbi.ti,ab. [tbi in title or abstract only] (13096)

exp craniocerebral trauma/ (120500)

head injuries, closed/(2621)

(head injur\$ adj3 closed).ti,ab. (2226)

or/1-9 (128583)

limit 10 to ("all aged (65 and over)" or "aged (80 and over)") (19051)

exp aged/[includes MeSH terms 'aged 80 and over' and 'frail elderly'] (2356669)

advanced age\$.ti,ab. (11066)

advancing year\$.ti,ab. (154)

agedness.ti,ab. (4)

ag?ing.ti,ab. (140485)

elder\$.ti,ab. (181430)

retire\$.ti,ab. (13409)

pension\$.ti,ab. (3002)

(old\$ adj2 (age\$ or patient\$ or $\mathrm{m}$ ?n or wom?n or male $\$$ or female? or person $\$$ or people $\$$ or population)).ti,ab. (473217)

senior.ti,ab. (20069)

or/11-21 (2809465)

10 and 22 (23542)

exp "Quality of Life"/(119676)

(quality adj2 life\$).mp. [mp=title, abstract, original title, name of substance word, subject heading word, keyword heading word, protocol supplementary concept, rare disease supplementary concept, unique identifier] (199290) exp adaptation, psychological/ (102082)

attitude/(39275)

questionnaires/(304753)

exp Health Status Indicators/ (201237)

health status inventor\$.mp. (27)

Positive-negative evaluation.mp. (4)

pne.mp. (383)

HRQOL.ti,ab. (7595)

Rand 36.mp. (529)

SF12.mp. (160)

sf-36.ti,ab. (13380) 


\begin{tabular}{ll}
\hline 37 & qol.ti,ab. (19573) \\
38 & or/24-37 (747435) \\
39 & 23 and 38 (1378) \\
40 & remove duplicates from 39 (1314) \\
41 & limit 40 to english language \\
& $(1215)$ \\
& $(1614$ up-date) \\
\hline
\end{tabular}

\section{References}

1. Fu, T. S., Jing, R., McFaull, S. R., \& Cusimano, M. D. (2015). Recent trends in hospitalization and in-hospital mortality associated with traumatic brain injury in Canada: A nationwide, population-based study. The Journal of Trauma and Acute Care Surgery, 79(2), 449-454.

2. Mapping connections an understanding of neurological conditions in Canada. (2014) The national population health study of neurological conditions. Public Health Agency of Canada, Sept. Retrieved September 14, 2018, from http://www.mybrainmatters. ca/wp-content/uploads/Mapping_Connections.pdf

3. Yu, F., \& Richmond, T. (2005). Factors affecting outpatient rehabilitation outcomes in elders. J Nurs Scholarship, 37(3), 229-236.

4. Brown, M., Gordon, W. A., \& Haddad, L. (2000). Models for predicting subjective quality of life in individuals with traumatic brain injury. Brain Injury, 14(1), 5-19.

5. Thomas, M. D., Skilbeck, C. E., \& Slatyer, M. (2009). Pre-injury estimates of subjective quality of life following traumatic brain injury. Brain Injury, 23(6), 516-527.

6. Burckhardt, C. S., \& Anderson, K. L. (2003). The Quality of Life Scale (QOLS): Reliability, validity, and utilization. Health Qual Life Outcomes, 23(1), 60.

7. Botchway, E., Godfrey, C., Anderson, V., \& Catroppa, C. (2018). A systematic review of sleep-wake disturbances in childhood traumatic brain injury: Relationship with fatigue, depression and quality of life. Journal of Head Trauma Rehabilitation, 34, 1-16.

8. Hutchinson, M. G., Di Battista, A. P., McCoskey, J., \& Watlinh, E. S. (2012). Systematic review of mental health measures associated with concussive and subconcussive head trauma in former athletes. International Journal of Psychophysiology, 132, 55-61.

9. Voormolen, D. C., et al. (2018). The association between postconcussion symptoms and heath related quality of life in patients with mild traumatic brain injury. Injury, 50, 1383-1396.

10. Kruithof, N., et al. (2018). Validation and reliability of the abbreviated world health organization quality of life instrument (WHOQOL-BREF) in the hospitalized trauma population. Injury, 49(10), 1796-1804.

11. Baernholdt, M., Hinton, I., Yan, G., Rose, K., \& Mattos, M. (2012). Factors associated with quality of life in older adults in the United States. Quality of Life Research, 21(3), 527-534.

12. Vaidya, S. \& Boes, S. (2018). Measuring quality of life in children with spinal muscular atrophy: A systematic literature review. Quality of Life Research, 12, 3087-3094. Retrieved Oct 10, 2018 from https://www.ncbi.nlm.nih.gov/pubmed/30043243

13. Hunt, C., et al. (2017). Common data elements for concussion in tertiary care: Phase one in Ontario. Canadian Journal of Neurological Sciences, 44(6), 676-683.

14. National Institute of Neurologic Disorders and Stroke (NINDS). (2017). NINDS common data elements. Bethesda, MD. Retrieved Sept 30, 2018, from http://www.commondataelements.ninds.nih. gov.myaccess.library.utoronto.ca/\#page=Default.
15. Moher, D. J., et al. (2009). Preferred reporting items for systematic reviews and meta-analyses: The PRISMA statement. Annals of Internal Medicine, 151(4), 264-269.

16. PROPSPERO International prospective register of systematic reviews. (2009). National Institute for Health Research. Retrieved Sept 20, 2018 from https://www.crd.york.ac.uk/prospero/

17. COSMIN from https://www.cosmin.nl/tools/guideline-conducting -systematic-review-outcome-measures/?portfolioCats=19)

18. Downs, S. H., \& Black, N. (1998). The feasibility of creating a checklist for the assessment of the methodological quality both of randomised and non-randomised studies of health care interventions. Journal of Epidemiology and Community Health, 52(6), 377-384.

19. Marinho-Buzelli, A. R., Bonnyman, A. M., \& Verrier, M. C. (2015). The effects of aquatic therapy on mobility in individuals with neurological diseases: A systematic review. Clinical Rehabilitation, 29(8), 741-751.

20. Smith, T. O., et al. (2017). A systematic review of the physical activity assessment tools used in primary care. Family Practice, 34(4), 384-391.

21. Topolovec-Vranic J., et al. (2012).Traumatic brain injury among people who are homeless: a systematic review. BMC Public Health. Retrieved Feb 28, 2018 from https://bmcpublichealth .biomedcentral.com/track/pdf/10.1186/1471-2458-12-1059.

22. Matuseviciene, G., Eriksson, G., \& DeBoussard, C. N. (2016). No effect of an early intervention after mild traumatic brain injury on activity and participation: A randomized controlled trial. Journal of Rehabilitation Medicine, 48(1), 19-26.

23. McHugh M. L. (2012). Interrater reliability: The kappa statistic. Biochemical Medicine, 22(3), 276-282. Retrieved July 10, 2018 from https://www.ncbi.nlm.nih.gov/pmc/articles/PMC3900052/

24. Azouvi, P., et al. (2016). Disability and health-related qualityof-life 4 years after a severe traumatic brain injury: A structural equation modeling analysis. Brain Injury, 30(13-14), 1665-1671.

25. Brown, M., et al. (2004). Participation objective, participation subjective a measure of participation combining outsider and insider perspectives. Journal of Head Trauma Rehabilitation, 19(6), 459-481.

26. Cnossen, M. C., et al. (2017). Comparing health-related quality of life of Dutch and Chinese patients with traumatic brain injury: Do cultural differences play a role? Health and Quality of Life Outcomes, 15(1), 1-10.

27. Grieve, R., et al. (2016). An evaluation of the clinical and costeffectiveness of alternative care locations for critically ill adult patients with acute traumatic brain injury. British Journal of Neurosurgery, 30(4), 388-396.

28. Haller, C. S., et al. (2017). Trajectory of disability and quality-oflife in nongeriatric and geriatric survivors after severe traumatic brain injury. Brain Injury, 31(3), 319-328.

29. Horner, M. D., et al. (2005). Patterns of alcohol use 1 year after traumatic brain injury: A population-based, epidemiological study. Journal of the International Neuropsychological Society, 11(3), 322-330.

30. Horner, M. D., et al. (2008). Predictors of psychological symptoms 1 year after traumatic brain injury: A population-based, epidemiological study. Journal of Head Trauma Rehabilitation, 23(2), 74-83.

31. Kristman, V. L., et al. (2016). Prognostic markers for poor recovery after mild traumatic brain injury in older adults: A pilot cohort study. Journal of Head Trauma Rehabilitation, 31(6), E33-E43.

32. Lin, Y. N., et al. (2016). Suitability of the quality of life after brain injury instrument for older people with traumatic brain injury. Journal of Neurotrauma, 33(14), 1363-1370.

33. Mar, J., et al. (2011). The impact of acquired brain damage in terms of epidemiology, economics and loss in quality of life. BMC Neurology, 11(46), 1-11. 
34. McCarthy, M. L., et al. (2006). Self-reported psychological health among adults with traumatic brain injury. Archives of Physical Medicine and Rehabilitation, 87(7), 953-961.

35. Muehlan, H., Wilson, L., \& von Steinbüchel, N. A. (2016). Rasch analysis of the QOLIBRI six-item overall scale. Assessment, 23(1), 124-130.

36. Pickelsimer, E. E., et al. (2006). A Population-based outcomes study of persons hospitalized with traumatic brain injury operations of the South Carolina traumatic brain injury follow-up registry. Journal of Head Trauma Rehabilitation, 21(6), 491-504.

37. Selassie, A. W., et al. (2003). Incidence of long-term disability following traumatic brain injury hospitalization, United States. Journal of Head Trauma Rehabilitation, 23(2), 123-131.

38. Stambrook, M., et al. (1993). Alternatives to the Glasgow coma scale as a quality of life predictor following traumatic brain injury. Archives of Clinical Neuropsychology, 8(2), 95-103.

39. Thompson, H. J., et al. (2012). Utilization and costs of health care after geriatric traumatic brain injury. Journal of Neurotrauma, 29(10), 1864-1871.

40. Toman, E., et al. (2017). Vitamin D deficiency in traumatic brain injury and its relationship with severity of injury and quality of life: A prospective, observational study. Journal of Neurotrauma, 34(7), 1448-1456.

41. Toyinbo, P. A., et al. (2016). Development and initial validation of military deployment-related TBI quality-of-life item banks. Journal of Head Trauma Rehabilitation, 31(1), 52-61.

42. Weber, K. T., et al. (2016). Predictors of quality of life after moderate to severe traumatic brain injury. Arquivos de Neuro-Psiquiatria, 74(5), 409-415.

43. von Steinbuechel, N., et al. (2012). QOLIBRI Overall Scale: A brief index of health-related quality of life after traumatic brain injury. Journal of Neurology, Neurosurgery and Psychiatry, 83(11), 1041-1047.

44. Bryan, S., Broesch, J., Dalzell, K., et al. (2013). What are the most effective ways to measure patient health outcomes of primary health care integration through PROM (Patient Reported Outcome Measurement) instruments? Resource document. Government of Canada. http://www.cihr-irsc.gc.ca/e/47174.html

45. Findler, M., Cantor, J., Haddad, L., et al. (2001). The reliability and validity of the SF-36 health survey questionnaire for use with individuals with traumatic brain injury. Brain In., 15, 715-723.

46. Ware, J., Jr., Kosinski, M., \& Keller, S. D. (1996). A 12-Item Short-Form Health Survey: Construction of scales and preliminary tests of reliability and validity. Medical Care, 34, 220-233.

47. Chiu, W. T., Huang, S. J., Hwang, H. F., et al. (2006). Use of the WHOQOL-BREF for evaluating persons with TBI. Journal of Neurotrauma, 23(11), 1609-1620.

48. Lin, Y., Hwang, H., Chen, H., et al. (2016). Suitability of the quality of life after brain injury instrument for older people with traumatic brain injury. Journal of Neurotrauma, 33, 1363-1370.

49. QOLIBRI. (2019). QOLIBRI. Resource document. QOLIBRI http://qolibrinet.com/

50. von Steinbuchel, N., Wilson, L., Gibbons, H., et al. (2010). Quality of life after brain injury (QOLIBRI) - Scale validity and correlates of quality of life. Journal of Neurotrauma, 27, 1157-1165.

51. Brazier, J., Jones, N., \& Kind, P. (1993). Testing the validity of the EuroQOL and comparing it with the SF-36 health survey questionnaire. Quality of Life Research, 2, 169-180.

52. EuroQol Group. (1990). EuroQol-a new facility for the measurement of health-related quality of life. Health Policy, 16(3), 199-208.

53. van Agt, H., Essink-Bot, L., Krabbe, P., et al. (1994). Test-retest reliability of health state valuations collected with the EuroQol questionnaire. Social Science and Medicine, 39, 1537-1544.

54. American Thoracic Society. (2007). Sickness impact profile. Resource document. American Thoracic Society. http://qol.thora cic.org/sections/instruments/pt/pages/sick.html
55. Bergner, M., Bobbitt, R. A., Pollard, W. E., et al. (1976). The sickness impact profile: validation of a health status measure. Medical Care, 14(1), 57-67.

56. van Baalen, B., Odding, E., van Woensel, M., et al. (2006). Reliability and sensitivity to change of measurement instruments used in a traumatic brain injury population. Clinical Rehabilitation, 20(8), 686-700.

57. Wielenga-Boiten, J., Heijenbrok-Kal, M., \& Ribbers, G. (2015). The relationship of health locus of control and health-related quality of life in the chronic phase after traumatic brain injury. Journal of Head Trauma Rehabilitation, 30(6), 424-431.

58. American Thoracic Society. (2007). Flanagan's quality of life scale. Resource document. American Thoracic Society. http:// qol.thoracic.org/sections/instruments/fj/pages/flan.html

59. Brown, M., \& Vandergoot, D. (1998). Quality of life for individuals with traumatic brain injury: Comparison with others living in the community. Journal of Head Trauma Rehabilitation, 13(4), $1-23$.

60. Bertisch, H., Rivera, F., Kisala, P., et al. (2017). Psychometric evaluation of the pediatric and parent-proxy Patient-Reported Outcomes Measurement Information System and the Neurology and Traumatic Brain Injury Quality of Life measurement item banks in pediatric traumatic brain injury. Quality of Life Research, 26(7), 1887-1899.

61. Gershon, R., Lai, J., Bode, R., et al. (2012). Neuro-QOL: quality of life item banks for adults with neurological disorders: Item development and calibrations based upon clinical and general population testing. Quality of Life Research, 21(3), 475-486.

62. National Institute of Neurological Disorder and Stroke (NNIDS). (2015). User manual for the quality of life in neurological disorders (Neuro-QoL) measures, version 2.0. Resource document. National Institute of Neurological Disorder and Stroke. http:// www.healthmeasures.net/images/neuro_qol/Neuro-QOL_User_ Manual_v2_24Mar2015.pdf

63. Victorson, D., Cavazos, J., Holmes, G., et al. (2014). Validity of the neurology quality-of-life (Neuro-QoL) measurement system in adult epilepsy. Epilepsy and Behaviour, 31, 77-84.

64. Hwang, H. F., et al. (2015). Risk factors for traumatic brain injuries during falls in older persons. Journal of Head Trauma Rehabilitation, 30(6), E9-E17.

65. Patrick, D., \& Deyo, R. (1989). Generic and disease specific measures in assessing health status and quality of life. Medical Care, 27(3), 217-232.

66. Ware, J. E., \& Gandek, B. (1998). Overview of the SF-36 Health Survey and the International Quality of Life Assessment (IQOLA) project. Journal of Clinical Epidemiology, 51(11), 903-912.

67. Ontario Brain Institute. Retrieved from http://braininstitute.ca/ research-data-sharing/brain-code

68. Keller, H. H., Østbye, T., \& Goy, R. (2004). Nutritional risk predicts quality of life in elderly community-living Canadians. Journals of Gerontology. Series A, Biological Sciences and Medical Sciences, 59(1), 68-74.

69. Engel, L., et al. (2016). Older adults' quality of life-Exploring the role of the built environment and social cohesion in community-dwelling seniors on low income. Social Science and Medicine, 164, 1-11.

70. Simpson-Jones, M. E., \& Hunt, A. W. (2018). Vision rehabilitation interventions following mild traumatic brain injury: A scoping review. Disability and Rehabilitation, 10, 1-17.

71. Arrieta, H., et al. (2018). Physical activity and fitness are associated with verbal memory, quality of life and depression among nursing home residents: Preliminary data of a randomized controlled trial. BMC Geriatrics, 18(1), 80 .

Publisher's Note Springer Nature remains neutral with regard to jurisdictional claims in published maps and institutional affiliations. 